\title{
Downregulation of IncRNA MALAT1 suppresses abnormal proliferation of small intestinal epithelial stem cells through miR-129-5p expression in diabetic mice
}

\author{
TI-DONG SHAN, ZI-BIN TIAN and YUE-PING JIANG \\ Department of Gastroenterology, The Affiliated Hospital of Qingdao University, \\ Qingdao University, Qingdao, Shandong 262000, P.R. China
}

Received September 27, 2019; Accepted January 8, 2020

DOI: $10.3892 / \mathrm{ijmm} .2020 .4492$

\begin{abstract}
The problems caused by diabetes mellitus (DM) and its related complications are gaining increasing attention. In our previous study, the abnormal proliferation of small intestinal epithelial cells (IECs) were observed in diabetic mice. However, little is known regarding the potential underlying mechanism. In the present study, the abnormal proliferation of IECs in DM and the marked upregulation of metastasis associated lung adenocarcinoma transcript 1 (MALAT1) was observed. Additionally, knockdown of MALAT1 significantly reduced abnormal IESC proliferation in DM mice. Bioinformatics analysis and luciferase reporter assays revealed that microRNA (miR)-129-5p was directly targeted by MALAT1. Moreover, the results of the bioinformatics prediction and luciferase assays demonstrated that MALAT1 directly interacted with SRY-box 9 (SOX9). Furthermore, MALAT1 silencing was observed to attenuate the abnormal proliferation of IESCs through the SOX9-mediated WNT/ $\beta$-catenin signaling pathway. Knockdown of MALAT1 downregulated SOX9 expression by binding to miR-129-5p, thereby inhibiting the abnormal proliferation of IESCs via the WNT/ $\beta$-catenin signaling pathway.
\end{abstract}

Correspondence to: Dr Ti-Dong Shan, Department of Gastroenterology, The Affiliated Hospital of Qingdao University, Qingdao University, 16 Jiang Su Road, Qingdao, Shandong 262000, P.R. China

E-mail: shantidong26@163.com

Abbreviations: lncRNA, long noncoding RNA; miRNA, microRNA; mRNA, messenger RNA; ceRNA, competing endogenous RNA; DM, diabetes mellitus; IECs, intestinal epithelial cells; IESCs, intestinal epithelial stem cells; STZ, streptozocin; qPCR, quantitative polymerase chain reaction; UTR, untranslated region; DAB, 3,3'-diaminobenzidine tetrahydrochloride

Key words: diabetes mellitus, lncRNA, microRNA, intestinal epithelial stem cell, proliferation

\section{Introduction}

Diabetes mellitus (DM) is a major metabolic disorder, affecting over 350 million people worldwide in 2017 (1). The increased incidence of DM is associated with an increased incidence of complications of diabetes, making DM one of the most important current public health issues (2). Diabetic enteropathy (DE) is a common complication of DM, and the majority of previous studies have examined neuron loss, which results in dysmotility and altered secretion within the entire gastrointestinal tract; therefore, it has been proposed that DE should be considered a panenteric disorder (3). However, in patients with DM, intestinal epithelial cells (IECs) often undergo significant changes. A number of recent studies have shown that DM is an independent risk factor for the occurrence and development of colorectal cancer $(4,5)$, supporting the hypothesis that there is an association between DM and the abnormal proliferation of intestinal epithelial stem cells (IESCs).

Long noncoding RNAs (lncRNAs) constitute a cluster of transcripts that are made of $>200$ nucleotides, have no protein-coding ability and are able to regulate gene expression at the transcriptional, epigenetic, and translational levels $(6,7)$. These aberrantly expressed lncRNAs may be involved in epigenetic regulatory processes, such as chromatin modification, $\mathrm{X}$ chromosome silencing and genetic imprinting and in the regulation of transcription, translation, protein activity, and RNA alternative splicing $(8,9)$. The lncRNA expression profiles of a variety of tumors are significantly different. In our previous study, the knockdown of lncRNA H19 inhibited the abnormal differentiation of small IECs in diabetic mice (10). Metastasis associated lung adenocarcinoma transcript 1 (MALAT1), a highly conserved lncRNA, is expressed at high levels in the majority of cells. Previous research suggests that MALAT1 is involved in the pathogenesis of various human diseases, especially cancer. A number of recent studies point to the involvement of MALAT1 in the proliferation of cancer cells, vascular smooth muscle cells, high glucose-induced endothelial cells and periodontal ligament stem cells (11-13). However, the role of MALAT1 in the proliferation of IESCs in DM requires further understanding. MicroRNAs (miRNAs) are a major class of short ( 22 nucleotides) noncoding RNAs that function to block protein translation and/or degrade 
their messenger RNA targets. They bind to complementary sequences in the 3'-untranslated regions (UTRs), 5'UTRs, and/or coding regions of target mRNAs (11). One of the most novel functions of lncRNAs is their ability to serve as competing endogenous RNAs (ceRNAs), which compete with coding RNAs for shared miRNAs, thus regulating the functions of these genes $(14,15)$. miRNAs direct a number of important processes that are associated with cellular growth, apoptosis, differentiation, metabolism and the immune response (16). Furthermore, miRNAs are known to have a pivotal role in DM $(10,17)$. Numerous studies have reported the roles of miR-129-5p (18-20). miR-129-5p is involved in lncRNA Trinucleotide repeat containing adaptor $6 \mathrm{C}$-antisense RNA 1-mediated processes and regulates Unc-5 netrin receptor B in thyroid cancer to influence cell proliferation, migration, and invasion (18). Although studies have investigated the functions of miR-129-5p in cancer, its role in IESCs of DM remains largely unclear. Therefore, the present study investigated whether MALAT1 functions as a miRNA sponge by regulating the proliferation of IESCs in DM.

IESCs are located in the intestinal crypt, which maintains intestinal epithelial balance by regulating its own proliferation and differentiation $(18,21)$. The normal proliferation of IESCs is maintained by highly specialized and well-regulated signaling cascades. The Wnt pathway is a classical pathway in the IEC, and this pathway acts primarily on IESCs to promote intestinal epithelial proliferation. Additionally, deregulated Wnt signaling is involved in the pathophysiological processes of numerous diseases, including the occurrence and development of cancer (22). Recent evidence suggests that Wnt/ $\beta$-catenin signaling is activated under diabetic conditions (23) and that increased proliferation of IECs in diabetic rats has been associated with the accumulation of $\beta$-catenin (23). In our previous study, the abnormal proliferation of IECs in DM mice was observed (24); however, the potential mechanisms underlying the association between $\mathrm{Wnt} / \beta$-catenin signaling pathway activation and abnormal IESC proliferation in DM are still poorly understood.

Numerous studies on MALAT1 have examined its role in the progression and prognosis of cancer (25-27). Despite the aforementioned findings, the role of MALAT1 in IESCs of DM needs to be investigated. In the present study, MALAT1 expression was significantly elevated in the IESCs of DM mice. Furthermore, it was demonstrated that MALAT1 acts as a 'molecular sponge' for miR-129-5p to regulate the abnormal proliferation of IESCs via the Wnt signaling pathway.

\section{Materials and methods}

Streptozocin (STZ)-induced DM mice model. A total of 96 8-week-old male C57BL/6J mice (weight, 20-40 g) were obtained from the Animal Laboratory Center in The Affiliated Hospital of Qingdao University (Qingdao, China). All animals were maintained in a thermostatically controlled room with a 12-h light/dark cycle. Diabetes was induced by daily intraperitoneal injection of STZ (Sigma-Aldrich; Merck $\mathrm{KGaA} ; 70 \mathrm{mg} / \mathrm{kg}$ ) for 5 days $(10,17,28)$; and the mice in the control group received ip injections the same volume of citrate buffer $(0.1 \mathrm{~mol} / 1(10,17,28)$. DM in the experimental mice was defined as a fasting blood glucose $\geq 16.7 \mathrm{mmol} / \mathrm{l}$ for ten consecutive days $(10,17,28)$. Then, all mice were euthanized with an intraperitoneal injection of ketamine/xylazine (100/10 mg/kg body weight). The small intestines were carefully removed and flushed with $0.1 \mathrm{M}$ PBS $(\mathrm{pH}$ 7.4) for the isolation of primary IESCs. All experiments with mice were approved by the Animal Care Committee of The Affiliated Hospital of Qingdao University.

RNA extraction and reverse transcription-quantitative polymerase chain reaction $(R T-q P C R)$. Total RNA was extracted from tissue samples and cell lines using TRIzol reagent (Invitrogen; Thermo Fisher Scientific, Inc.). Then, RT was performed with PrimeScript $^{\mathrm{TM}}$ RT Master mix (Takara Biotechnology Co., Ltd.). The RT conditions were as follows: $42^{\circ} \mathrm{C}$ for $5 \mathrm{~min}$ and $95^{\circ} \mathrm{C}$ for 10 sec. qPCR was performed on a CFX Connect ${ }^{\mathrm{TM}}$ real-time PCR detection system (Bio-Rad Laboratories, Inc.) using SYBR ${ }^{\circledR}$ Premix Ex Taq ${ }^{\mathrm{TM}}$ (Takara Biotechnology Co., Ltd.). The thermocycling conditions were as follows: Initial denaturation at $95^{\circ} \mathrm{C}$ for $5 \mathrm{~min}$, followed by 40 cycles of denaturation at $95^{\circ} \mathrm{C}$ for $15 \mathrm{sec}$ and annealing/elongation at $60^{\circ} \mathrm{C}$ for $30 \mathrm{sec}$. miRNA expression levels were measured using the SYBR PrimeScript ${ }^{\mathrm{TM}}$ miRNA RT-PCR kit (Takara Biotechnology Co., Ltd.). miRNA samples were normalized to U6. Each experiment was repeated six times. The primers are described in Table SI. The data were analyzed using the $2^{-\Delta \Delta \mathrm{Cq}}$ method (29).

Bioinformatics analysis. DIANA-LncBase Predicted v.2 (http://diana.imis.athena-innovation.gr/DianaTools/ index.php?r=lncBase/index) and TargetScan 7.2 (http://www. targetscan.org/) were used to predict the putative target genes for MALAT1 and miR-129-5p.

Culture of cell lines. CT26 cells, NIH 3T3 cells and 293T cells were obtained from American Type Culture Collection. These cell lines were all cultured under standard culture conditions as described previously $(10,17)$. Cell lines were cultured in DMEM (Invitrogen; Thermo Fisher Scientific, Inc.) with 10\% FBS (Gibco; Thermo Fisher Scientific, Inc.) and 1\% penicillin/streptomycin. Cells were grown in a $95 \%$ air, $5 \% \mathrm{CO}_{2}$ atmosphere at $37^{\circ} \mathrm{C}$.

Primary IESC isolation and culture. Primary IESCs were isolated from the small intestines of mice and cultured in Matrigel as described previously $(10,17,30,31)$.

Cell transfection. The siRNAs targeting MALAT1 were purchased from GenePharma (si\#1 and si\#2; Shanghai GenePharma Co., Ltd.). CT26 cells and primary IESCs were seeded in six-well plates 1 day prior to transfection. The siRNAs (15 nM), miRNA mimic (15 nM) and inhibitor $(15 \mathrm{nM})$ were transfected into cells according to the Lipofectamine 3000 transfection reagent protocol (Thermo Fisher Scientific, Inc.). The miRNA mimic (agomiR-129-5p) and inhibitor (antagomiR-129-5p) were all purchased from Shanghai GenePharma Co., Ltd. The silencing efficiency was evaluated at $48 \mathrm{~h}$ following transfection using RT-qPCR. Each experiment was repeated six times.

Dual-luciferase reporter plasmid transfection. The MALAT1 and SRY-box 9 (SOX9) wild-type (WT) sequences with 
potential miR-129-5p-binding sites were amplified from the genomic DNA of NIH 3T3 cells and cloned into the pmiR-RB-REPORT ${ }^{\mathrm{TM}}$ plasmid (Guangzhou RiboBio Co., Ltd.). A plasmid containing a potential miR-129-5p-binding site with a mutation was used as the negative control (Guangzhou RiboBio Co., Ltd.). Mutations were introduced with the KOD-plus mutagenesis kit (Toyobo Life Science). Measurements of firefly and Renilla luciferase activity were performed using the Dual-Luciferase Reporter Assay system (Promega Corporation). Briefly, A total of $48 \mathrm{~h}$ after cell transfection, for the Dual-Luciferase Reporter assay, the firefly luciferase reporter was measured first by adding Luciferase Assay Reagent II to generate a stabilized luminescent signal. After the firefly luminescence was quantified for $3 \mathrm{~min}$, the reaction was quenched, and the Renilla luciferase reaction was simultaneously initiated by adding Stop \& Glo $^{\circledR}$ reagent to the same tube. The Stop \& Glo ${ }^{\circledR}$ reagent also produced a stabilized signal from the Renilla luciferase protein, which decayed slowly over the course of the measurement. The luciferase efficiency was evaluated at $2 \mathrm{~min}$ following Stop \& $\mathrm{Glo}^{\circledR}$ reagent using SpectraMAX Multifunctional Microplate Reader (Molecular Devices). Each experiment was repeated six times.

Downregulating the expression of MALAT1 in vivo. A total of $120 \mathrm{C} 57 \mathrm{BL} / 6 \mathrm{~J}$ mice were randomly divided into five groups, with 24 in each group. All mice received a tail vein injection once a day for 3 days. The Con-NS group comprised control mice receiving saline $(0.9 \%$; same volume as the experimental group) injections $(14,15)$, and the DM-NS group comprised DM mice receiving saline $(0.9 \%$; same volume as the experimental group) injections (14,15); the DM-siRNA (si\#1 and si\#2) mice received injections of MALAT1 siRNAs $(80 \mathrm{mg} / \mathrm{kg}$ body weight $(14,15)$, and the DM-CT mice received injections of antagomiR-129-5p and MALAT1 siRNAs ( $80 \mathrm{mg} / \mathrm{kg}$ body weight $(14,15)$. In each group, six mice were euthanized with an intraperitoneal injection of ketamine/xylazine $(100 / 10 \mathrm{mg} / \mathrm{kg}$ body weight) on day 0 (prior to injection), days 2, 4 and 6 for further study. Each experiment was repeated six times.

Fluorescence in situ hybridization. A DIG-labeled LNA-MALAT1 probe was synthesized by Bersinbio (Guangzhou,China.) and the probe sequences are available upon request. In brief, a 5-mm section of paraffin-embedded tissues was incubated with 50\% methanol in PBST (0.1\% Tween-20) solution for $5 \mathrm{~min}, 30 \%$ methanol for $5 \mathrm{~min}$, PBST solution for 5 min and then with 4\% paraformaldehyde in PBS solution for $20 \mathrm{~min}$ at room temperature. The tissues was washed twice with PBST for $5 \mathrm{~min}$ at room temperature and then followed by the treatment with proteinase K $(15 \mu \mathrm{g} / \mathrm{ml}$; New England Biolabs) at $37^{\circ} \mathrm{C}$ for $15 \mathrm{~min}$. After being washed three times with PBS and dried with ethanol, the section was hybridized using $30 \mathrm{nM}$ LNA-MALAT1 probe at $55^{\circ} \mathrm{C}$ for $1 \mathrm{~h}$. After three incubations with $\mathrm{SCC}$ buffer at $60^{\circ} \mathrm{C}$ for $30 \mathrm{~min}$, the samples were washed with PBST (PBS containing 0.1\% Tween-20) for $15 \mathrm{~min}$ three times at room temperature. The section was then incubated with anti-DIG-AP (cat. no. 11093274910; 1:300; Roche Diagnostics) at $4^{\circ} \mathrm{C}$ overnight. Then, the section was stained with NBT/BCIP (Thermo Fisher Scientific, Inc.) at $30^{\circ} \mathrm{C}$ for $2 \mathrm{~h}$, and the reaction was stopped with stop-buffer. When the section was dried with ethanol, the expression of
MALAT1 was determined using diaminobenzidine solution (1:900; Boster Biological Technology) for $3 \mathrm{~min}$ at room temperature, and the staining intensity was observed using a fluorescence microscope (Olympus Corporation). The staining was quantified by counting the number of positive cells at a magnification of $x 400$. Each experiment was repeated six times.

Immunohistochemistry. A 5-mm section was prepared from the paraffin-embedded intestinal section, and hematoxylin and eosin (H\&E) staining was further used for histological analysis. In brief, fresh tissue was fixed with $4 \%$ paraformaldehyde for $24 \mathrm{~h}$ at room temperature, then dehydrated with a gradient alcohol series $(75 \%$ alcohol for $4 \mathrm{~h}, 85 \%$ alcohol for $2 \mathrm{~h}, 90 \%$ alcohol for $2 \mathrm{~h}, 95 \%$ alcohol for $1 \mathrm{~h}$ ), absolute ethanol II for $30 \mathrm{~min}$, alcohol benzene for 5-10 min, xylene for 5-10 min, and wax for $3 \mathrm{~h}$; the wax-soaked tissue was embedded and stored at $-20^{\circ} \mathrm{C}$. After the wax had solidified, it was paraffin embedded and sliced. For immunohistochemistry, sections were placed in $1 \%$ hydrogen peroxide in PBS for $10 \mathrm{~min}$ and then placed in citrate buffer in a pressure cooker for 45 min (Beyotime Institute of Biotechnology). Goat serum (5-10\%; Beyotime Institute of Biotechnology) was applied for $30 \mathrm{~min}$ at room temperature, and then sections were incubated with anti-BrdU (cat. no. 560210; 1:200; BD Biosciences; Becton, Dickinson and Company,) and anti-SOX9 antibody (cat. no. 82630; 1:250; Cell Signaling Technology, Inc.) antibodies overnight at $4^{\circ} \mathrm{C}$. The tissue was then incubated with EnVision+/HRP/Rb (Dako; Agilent Technologies, Inc.) for $30 \mathrm{~min}$ at room temperature. Slides were developed using 3,3-diaminobenzidine tetrahydrochloride (DAB) and counterstained with hematoxylin. The H\&E-stained sections were imaged with a light microscope BX51 (Olympus Corporation) to measure the length of villi and the level of cell proliferation. The stained sections were quantified by counting the number of positive cells at a magnification of $\times 400$ in 10 contiguous, well-oriented intestinal crypts by an examiner blinded to sample identity. Each experiment was repeated six times.

Protein extraction and western blotting. Total protein from tissues and cells was isolated in RIPA Buffer (Thermo Fisher Scientific, Inc.) containing a protease inhibitor cocktail (Roche Applied Science). Protein samples ( $40 \mu \mathrm{g} / \mathrm{sample}$ ) were separated on $10 \%$ SDS-PAGE gels. The separated proteins were transferred onto polyvinylidene fluoride membranes and blocked with 5\% skim milk at room temperature for $1 \mathrm{~h}$. Blots were incubated at $4^{\circ} \mathrm{C}$ overnight with primary antibodies: Anti- $\beta$-catenin antibody (cat. no. 8480S; 1:1,000), anti-SOX9 antibody (cat. no. 82630; 1:1,000), anti-cyclin D1 antibody (cat. no. 55506S; 1:1,000), anti-cyclin-dependent kinase 2 (CDK2) antibody (cat. no. 2546; 1:1,000), anti-cell division cycle 42 (CDC42) antibody (cat. no. 2466; 1:1,000), and anti- $\beta$-actin antibody (cat. no. 4970; 1:1,000) (all from Cell Signaling Technology, Inc.). After three washes with TBS-T, the membranes were washed and incubated for $1 \mathrm{~h}$ with horseradish peroxidase-conjugated secondary antibody (cat. no. $7074 \mathrm{~S}$; Cell Signaling Technology, Inc.) at $37^{\circ} \mathrm{C}$. The blots were visualized using an enhanced chemiluminescence Ultra Western HRP Substrate kit (cat. no. WBULS0100; EMD Millipore) and autoradiography with X-ray film. 
A
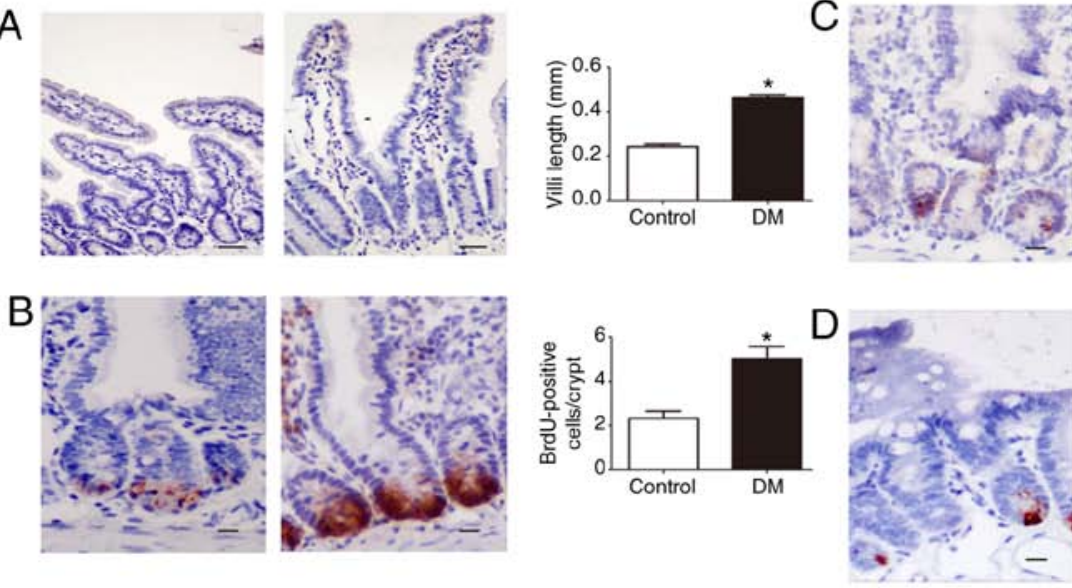
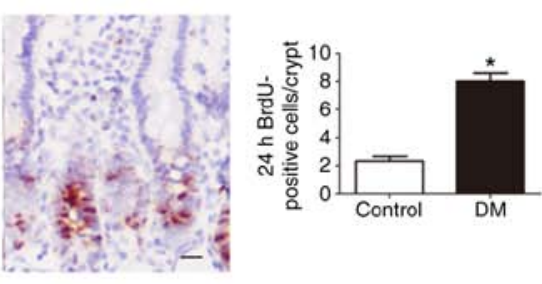

E
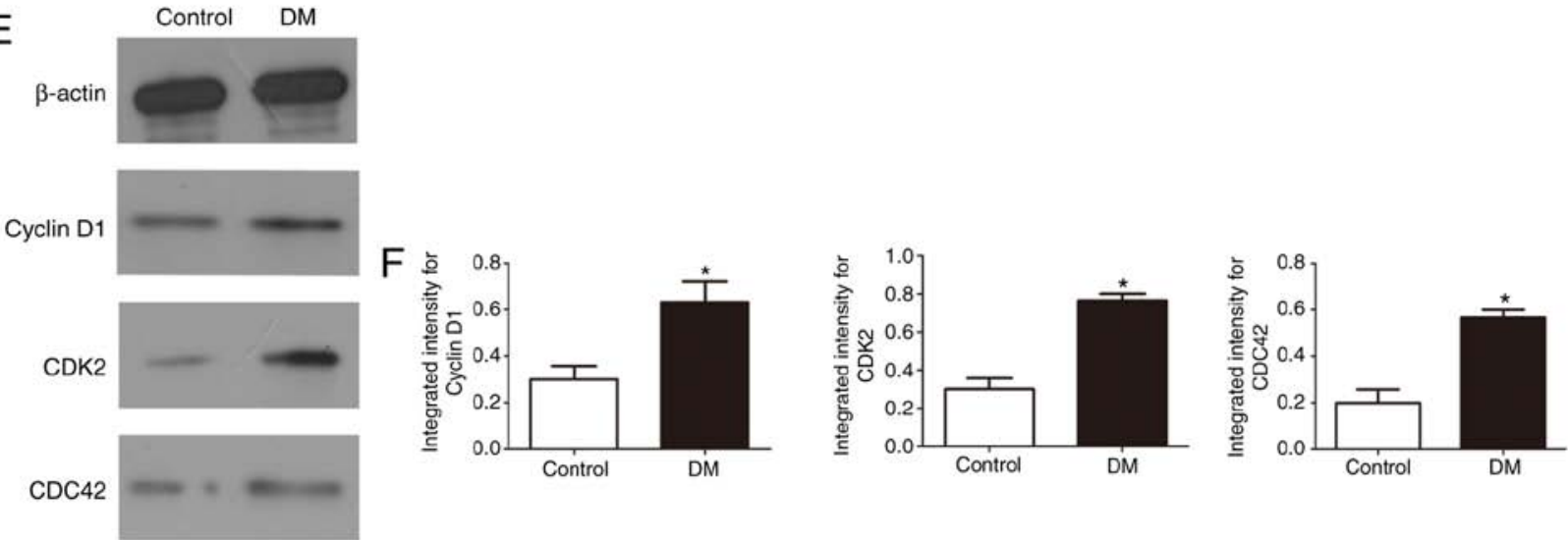

Figure 1. Abnormal proliferation of IECs in DM mice. (A) Immunostaining shows a longer villi length in DM mice. BrdU analysis showed that the BrdU positivity of intestinal crypts in DM mice increased significantly compared with that in the control group after (B) $1 \mathrm{~h}$ and (C) $24 \mathrm{~h}$ of BrdU injection. (D) The number of SOX9-positive IECs in the crypts of DM mice was significantly elevated compared with that of the control group. (E) The protein expression of cyclin D1, CDK2 and CDC42 was observed in the IECs of the DM mice compared with the control group, and (F) quantified. Scale bar, $50 \mu$ m; mean \pm SD, $\mathrm{n}=6$; ${ }^{*} \mathrm{P}<0.05$. DM, diabetes mellitus; IECs, intestinal epithelial cells; Sox9, SRY-box 9; CDK2, cyclin-dependent kinase 2; CDC42, cell division cycle 42.

Protein quantification was analyzed by Quantity One software version 4.6.2 (Bio-Rad Laboratories, Inc.) and the intensity values were normalized to $\beta$-actin. Each experiment was repeated six times.

Statistical analysis. Results are expressed as the mean \pm standard deviation and analyzed using the statistical software package (SAS 8.0 for Windows; SAS Institute, Inc.). Comparisons between groups were analyzed using a Student's test and multiple group comparisons were analyzed using one-way ANOVA with Tukey's post hoc test. $\mathrm{P}<0.05$ was considered to indicate a statistically significant difference.

\section{Results}

Abnormal proliferation of IECs in DM mice. To further evaluate IEC proliferation in DM, immunostaining was used to measure the length of the villi. The results showed that the length of the villi was significantly increased in DM mice compared with that in control mice $(\mathrm{P}<0.05$; Fig. 1A). Moreover, BrdU (intraperitoneal) injection into mice was used to label the S-phase cells of the intestinal epithelium. BrdU analysis showed that the BrdU positivity of intestinal crypts in DM mice increased significantly compared with that in the control group after $1 \mathrm{~h}$ of $\mathrm{BrdU}$ injection $(\mathrm{P}<0.05$; Fig. $1 \mathrm{~B})$. Additionally, the number of BrdU-positive cells in DM mice increased significantly after $24 \mathrm{~h}(\mathrm{P}<0.05$; Fig. $1 \mathrm{C})$. To detect a significant increase in intestinal cell proliferation, SOX9 staining was performed, which is a marker for the crypt cell population containing stem and progenitor cells. The crypts in the IECs of the DM mice contained an increased number of SOX9-positive cells compared with those of the control mice $(\mathrm{P}<0.05$; Fig. 1D). Based on the observed abnormal proliferation of IECs, the levels of several important cell cycle-related proteins were determined. An increased expression of cyclin D1, CDK2, and CDC42 was observed in the IECs of the $\mathrm{DM}$ mice compared with the control group $(\mathrm{P}<0.05$; Fig. $1 \mathrm{E}$ and F). These findings suggest that the abnormal proliferation of stem cells in the crypt may be responsible for the elongation of villi in DM mice.

MALAT1 is upregulated in the IESCs of DM mice. To determine whether MALAT1 is expressed in the IESCs of DM mice, its expression profile was examined. Interestingly, RT-qPCR analysis revealed that MALAT1 levels were significantly upregulated in the IESCs of DM compared with normal tissues $(\mathrm{P}<0.05$; Fig. 2A). Fluorescence in situ hybridization of a DIG-labeled LNA-MALAT1 probe further showed that 
A

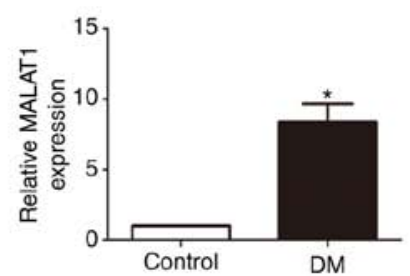

B

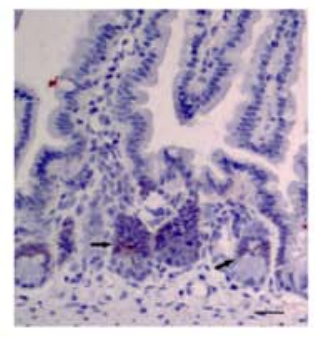

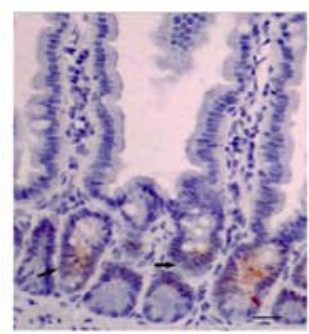

C

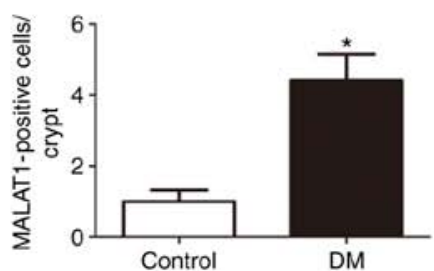

Figure 2. Abnormal MALAT1 expression in the IESCs of DM mice. (A) The expression level of MALAT1 was significantly higher in the IESCs of the DM group. (B) In situ hybridization shows the localization of MALAT1 (black arrows) and that (C) MALAT1 is highly expressed in DM mice compared with the control group. Scale bar, $50 \mu \mathrm{m}$; mean $\pm \mathrm{SD}, \mathrm{n}=6$; ${ }^{*} \mathrm{P}<0.05$. DM, diabetes mellitus; IESCs, intestinal epithelial stem cells; MALAT1, metastasis associated lung adenocarcinoma transcript 1 .

MALAT1 was predominantly localized to the cytoplasm of the intestinal crypt and that expression of MALAT1 in DM mice was significantly increased ( $\mathrm{P}<0.05$; Fig. $2 \mathrm{~B}$ and $\mathrm{C}$ ). Therefore, it was hypothesized that MALAT1, whose function is still not fully understood, plays an important role in the abnormal proliferation of IECs in DM mice.

Knockdown of MALAT1 inhibits the abnormal proliferation of IESCs in DM mice. To study the functional role of MALAT1 in the IESCs of DM, knockdown of MALAT1 in primary IESCs and CT26 cells was conducted. RT-qPCR showed that siRNA-mediated knockdown of MALAT1 significantly downregulated the expression of MALAT1 in both cell lines $(\mathrm{P}<0.05$; Fig. 3A). Additionally, tail vein injections of two siRNAs against MALAT1 into DM mice were performed. MALAT1 expression in the IESCs of DM-siRNAs mice was significantly downregulated at 2, 4 and 6 days compared to that in DM-NS mice $(\mathrm{P}<0.05$; Fig. 3B). MALAT1 expression on the 4th day after DM-siRNA injection was similar to that in the Con-NS mice. On the 4th day after DM-siRNA injection, BrdU was injected into DM-siRNA mice. One hour after the BrdU injection, the increase in BrdU positivity in the intestinal crypts was significantly inhibited in the DM-siRNA mice $(\mathrm{P}<0.05$; Fig. $3 \mathrm{C})$ and close to the levels observed in the Con-NS mice $(\mathrm{P}<0.05$; Fig. 3C). Additionally, SOX9 expression was measured using immunohistochemistry, and the expression of SOX9-positive cells in DM-siRNA mice was significantly decreased after siRNA administration $(\mathrm{P}<0.05$; Fig. 3D). These data indicate that MALAT1 may be involved in IESC proliferation in DM mice.

miR-129-5p directly binds and downregulates MALAT1. To further investigate the potential mechanism by which MALAT1 contributes to the abnormal proliferation of IESCs, DIANA-LncBase Predicted v.2 and the TargetScan database were used to predict a MALAT1 microRNA target and selected miR-129-5p ( $\mathrm{P}<0.05$; Fig. 4A). To verify the prediction, wild-type (MALAT1-WT) and miR-129-5p-binding-site mutant (MALAT1-MUT) MALAT1 luciferase reporters were constructed. As shown in Fig. 4B-D, miR-129-5p expression significantly attenuated the luciferase activity of the reporter with WT MALAT, but did not attenuate that of the mutant reporter $(\mathrm{P}<0.05)$. To further assess the potential association between miR-129-5p and MALAT1, primary IESCs and CT26 cells were transfected with antagomiR-129-5p or
agomiR-129-5p. It was demonstrated that restoration of miR-129-5p significantly reduced MALAT1 levels, whereas antagonism of miR-129-5p increased MALAT1 expression $(\mathrm{P}<0.05$; Fig. 4E and F). Taken together, these results indicate that MALAT1-mediated promotion of IESC proliferation is partly dependent on miR-129-5p sponging.

miR-129-5p regulates $W N T / \beta$-catenin signaling by targeting SOX9. The WNT/ $\beta$-catenin signaling pathway is essential for maintaining the development and homeostasis of IECs. Overexpression of miR-129-5p in primary IESCs and CT26 cells was performed and it was demonstrated that $\beta$-catenin mRNA and protein expression levels decreased. Inhibition of miR-129-5p expression resulted in the significant upregulation of $\beta$-catenin expression levels $(\mathrm{P}<0.05$; Fig. 5A-C). SOX9 was identified as a downstream target of miR-129-5p using the TargetScan (http://www.targetscan.org) online database. There are two putative SOX9 binding sites within miR-129-5p: Regions 599-605 and 608-614 (Fig. 5D). Activity analysis demonstrated that luciferase expression in IESCs and CT26 cells that were cotransfected with miR-129-5p and the SOX9-WT plasmid were significantly decreased compared with that of the cells cotransfected with miR-129-5p and the SOX9-MUT plasmid or transfected with the SOX9-WT plasmid alone $(\mathrm{P}<0.05$; Fig. 5E). To further assess the potential association between miR-129-5p and SOX9, cells were transfected with antagomiR-129-5p or agomiR-129-5p. As shown in Fig. 5F, forced expression of miR-129-5p significantly decreased SOX9 mRNA expression, while inhibition of miR-129-5p expression significantly increased SOX9 expression at the mRNA level $(\mathrm{P}<0.05)$; likewise, the protein expression of SOX9 was significantly decreased and increased, respectively $(\mathrm{P}<0.05$; Fig. $5 \mathrm{G}$ and $\mathrm{H})$. Our previous study showed that SOX9 regulates $\mathrm{WNT} / \beta$-catenin signaling in the IESCs of diabetic mice (25). These data further showed that miR-129-5p regulates $\mathrm{WNT} / \beta$-catenin signaling by targeting SOX9.

MALAT1 knockdown results in the downregulation of $\beta$-catenin expression through miR-129-5p in DM mice. First, primary IESCs and CT26 cells were transfected with siRNAs or cotransfected them with antagomiR-129-5p and siRNAs; the inhibition of MALAT1 significantly suppressed SOX9 and $\beta$-catenin expression, whereas inhibition of miR-129-5p partly abolished the silencing effect of MALAT1 knockdown on 

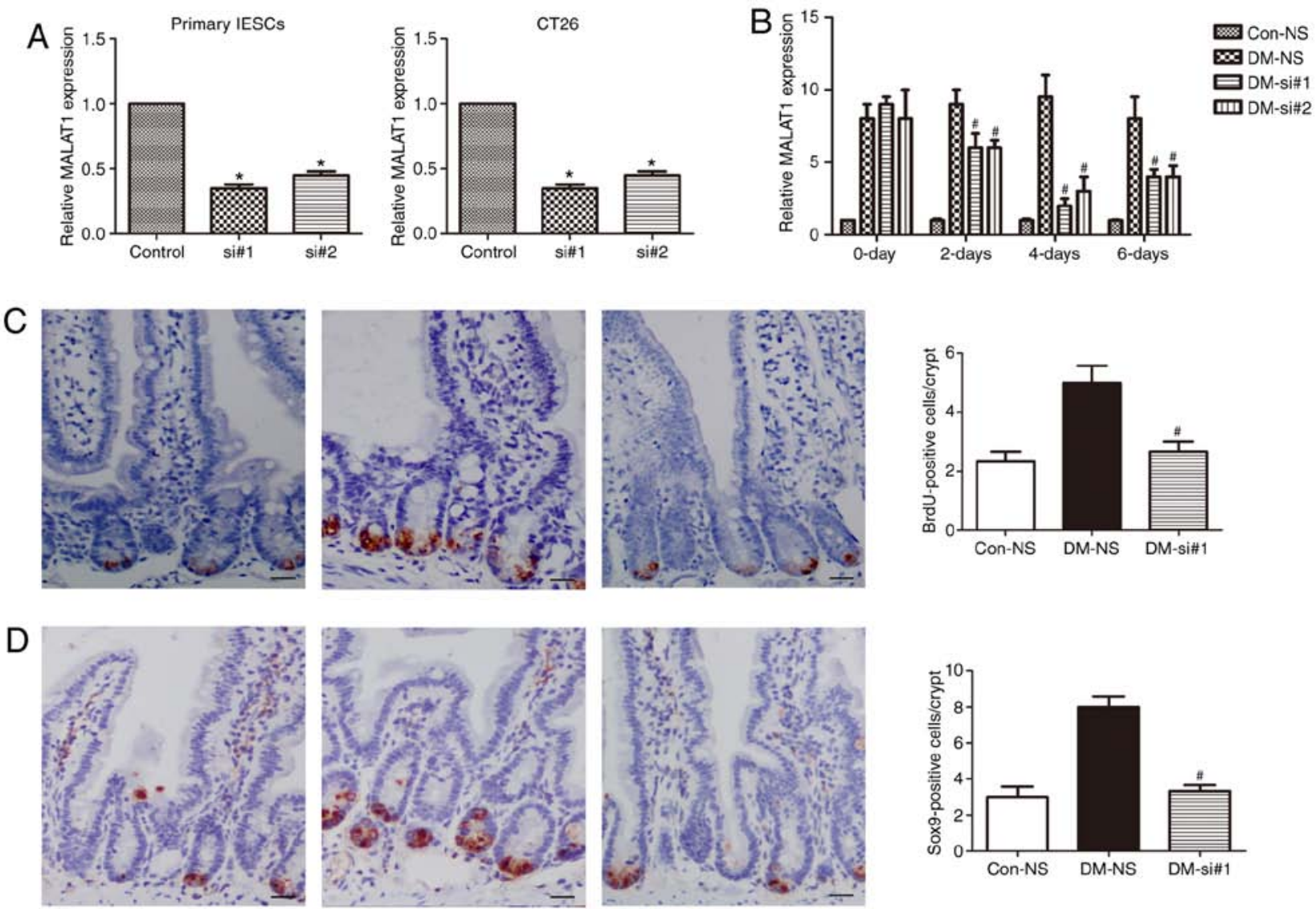

Figure 3. Abnormal proliferation of IESCs in DM mice is associated with overexpression of MALAT1. (A) The knockdown efficiencies in vitro after transfection of two siRNAs. (B) The knockdown efficiencies in vivo after tail vein injections. (C) BrdU positivity in the intestinal crypts was reduced in DM-siRNA mice. (D) The expression of Sox9-positive cells in DM-siRNA mice was significantly decreased compared with that in the DM group. Scale bars indicate $50 \mu \mathrm{m} ; \mathrm{n}=6$; ${ }^{*} \mathrm{P}<0.05$ compared to the control group; ${ }^{*} \mathrm{P}<0.05$ compared to the DM-NS group at the same time point. DM, diabetes mellitus; IESCs, intestinal epithelial stem cells; SOX9, SRY-box 9; MALAT1, metastasis associated lung adenocarcinoma transcript 1; siRNA, small interfering RNA; Con-NS, control mice receiving saline; DM-NS, DM mice receiving saline; DM-si, DM mice receiving siRNA.

SOX9 and $\beta$-catenin $(\mathrm{P}<0.05$; Fig. 6A-C). Then, to investigate the biological role of MALAT1 in the abnormal proliferation mechanism of IESCs in DM, siRNAs were subcutaneously injected into mice. The levels of SOX 9 and $\beta$-catenin protein in the DM-siRNA mice were significantly reduced compared with those in the DM-NS mice $(\mathrm{P}<0.05$; Fig. 6D and $\mathrm{E})$ and were similar to those in the Con-NS mice. Additionally, the expression levels of SOX 9 and $\beta$-catenin proteins were higher in DM-CT mice compared with in DM-siRNA mice $(\mathrm{P}<0.05$; Fig. 6D and E) and similar to those in DM-NS mice. More importantly, in our previous study, $\beta$-catenin was localized to the crypts of IECs (10). These results suggest that MALAT1 can regulate $\mathrm{WNT} / \beta$-catenin signaling by sequestering endogenous miR-129-5p in the IESCs of DM.

\section{Discussion}

As a complication of DM, DE is often present in diabetic patients, and there is still a lack of early diagnosis and effective treatment measures to mitigate the harmful and potentially irreversible effects of DE on the small intestine. A growing body of evidence indicates that abnormal expression of lncRNAs is associated with tumorigenesis and development, and that certain IncRNAs are associated with poor cancer prognosis (32-34). In fact, previous studies have demonstrated that MALAT1 can cause the tumorigenesis and development of multiple types of tumors, as well as abnormal development of vascular smooth muscle and endothelial cells $(12,13)$. However, the role of MALAT1 in the IESCs of DM is still is poorly understood. In the present study, a pathogenic role for MALAT1 was revealed in the IESCs of DM and its possible molecular mechanisms were elucidated. The findings suggested that MALAT1 is a specific lncRNA that causes the abnormal proliferation of IESCs in DM. In the present study, MALAT1 expression was significantly increased in the IESCs of DM mice. IESCs are located in the intestinal crypt of the intestinal epithelium and are mainly responsible for the renewal of IECs. Fluorescence in situ hybridization of a DIG-labeled LNA-MALAT1 probe showed that MALAT1 appears to be predominantly localized to the crypts of IECs and to the cytoplasm of crypt cells. Taken together, the data indicate that MALAT1 appears to play an important role in regulating the cell fate of the IESC in DM. Although the classical pathway for controlling IESC proliferation has been studied, little is known about the underlying molecular mechanisms controlling IESC proliferation $(10,17,24,35)$. In our previous studies, we found an increase in the number of goblet cells, Paneth cells, and absorptive cells and a reduction in endocrine cells in DM mice $(10,17)$. Immunostaining was used to show that the length of the villi was significantly increased in DM 
A

$$
\begin{aligned}
& \text { MALAT1-WT 5'- UUUGGGUGGGAAUGCAAAAAU - - } \\
& \text { miR-129-5p } \\
& \text { 3'- CGUUCGGGUCUGGCGUUUUUC - } \\
& \text { MALAT1-MUT } \\
& \text { 5' }- \text { UUUGGGUGGGAAUCGUUUUUU - }
\end{aligned}
$$
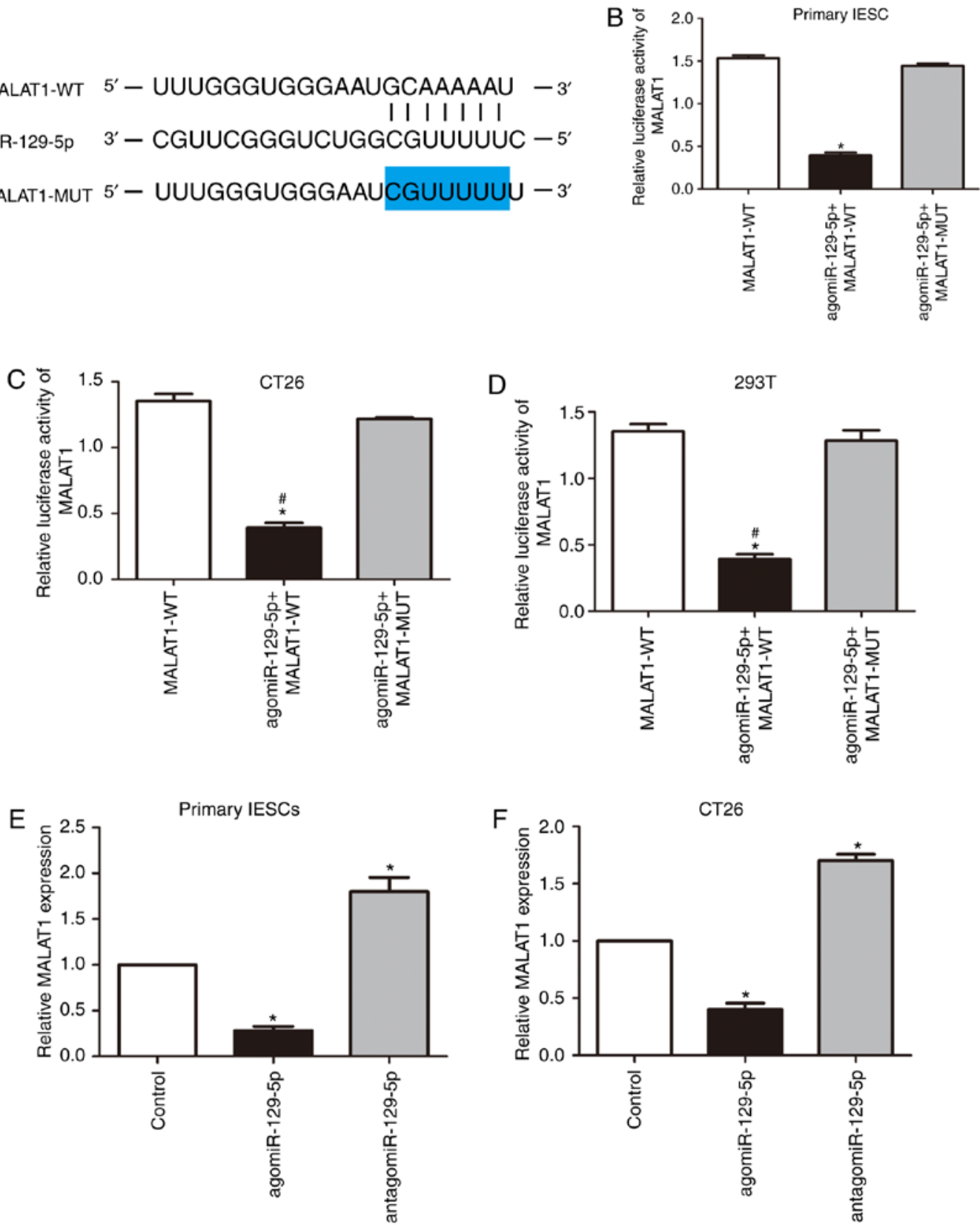

Figure 4. miR-129-5p directly targets MALAT1. (A) miR-129-5p binds to the MALAT1 sequence. Luciferase activity was detected in (B) primary IESCs, (C) CT26 cells and (D) 293T cells. Reverse transcription-quantitative polymerase chain reaction was used to analyze the association between miR-129-5p and MALAT1 in (E) IESCs and (F) CT26 cells. $n=6$; ${ }^{*} \mathrm{P}<0.05$ vs. control group; ${ }^{\prime \prime} \mathrm{P}<0.05$ vs. mutant group. IESCs, intestinal epithelial stem cells; MALAT1, metastasis associated lung adenocarcinoma transcript 1; miRNA/miR, microRNA; WT, wild type; MUT, mutant; agomiR, agonist miR; antagomiR, antagonist miR .

mice. Moreover, BrdU positivity was significantly higher in the intestinal crypts of DM mice than in those of normal mice after 1 and $24 \mathrm{~h}$. Given that IECs are highly dependent on IESC function, whether Sox 9 affects IESCs was investigated. It was observed that the crypts in the IECs of the DM mice contained an increased number of Sox9-positive cells compared with those of the control mice. The precise balance between IESC proliferation and the principal molecular determinant of IESC proliferation remains to be elucidated. Inspired by these results, it was hypothesized that MALAT1 may be involved in the abnormal proliferation of IESCs in DM. Using loss-of-function methods in vivo, it was revealed that MALAT1 plays a key role in the abnormal proliferation of IESCs in DM. Following siRNA injections into DM mice, the abnormal proliferation of IESCs was normalized according to the results of BrdU assays. These results indicate that inhibiting MALAT1 may be an effective method to prevent the abnormal proliferation of IESCs in DM mice. However, it remained plausible that other upregulated lncRNAs or even downregulated lncRNAs may exhibit large differences in the DM model. Additionally, the regulatory network of lncRNAs appears to be complex and may be highly dependent on the cellular context. Thus, more research is needed in the future.

Recently, emerging evidence has suggested that lncRNAs regulate miRNAs by functioning as endogenous sponges, and it has been experimentally demonstrated that miRNA targeting regulates the stability of lncRNAs $(36,37)$. In accordance with the ceRNA hypothesis, MALAT1 also functions as a decoy 
A
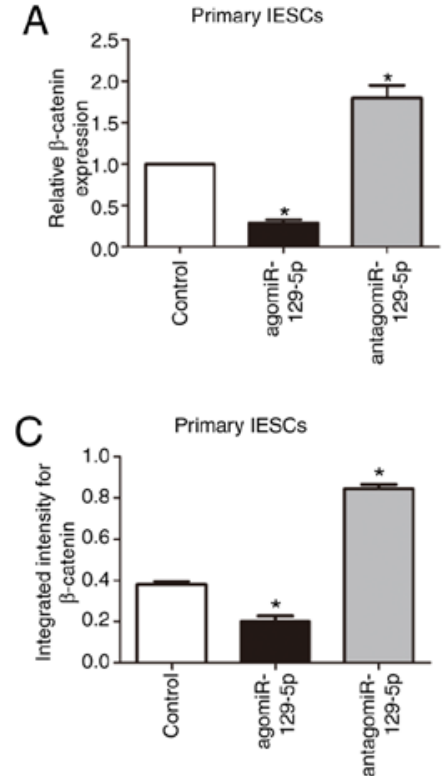

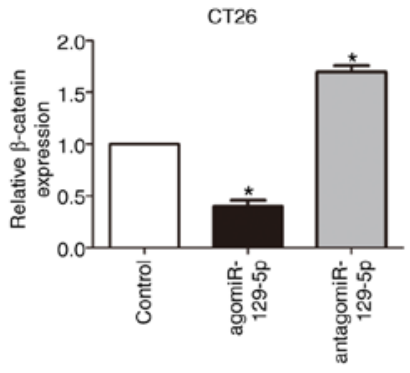

СТ26
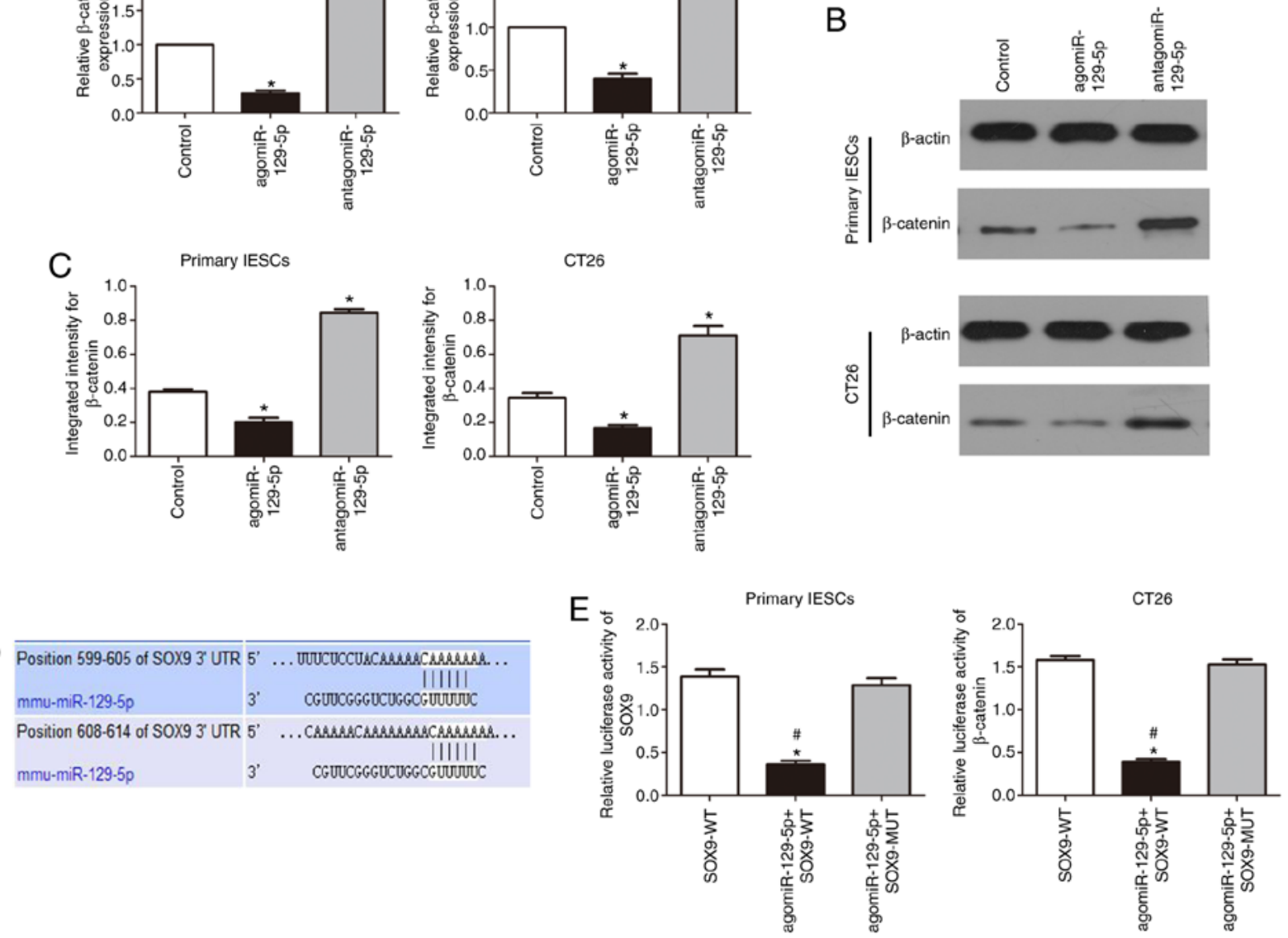
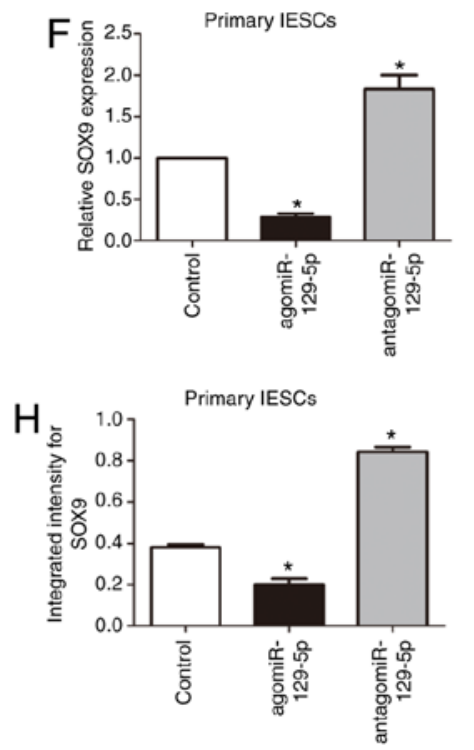

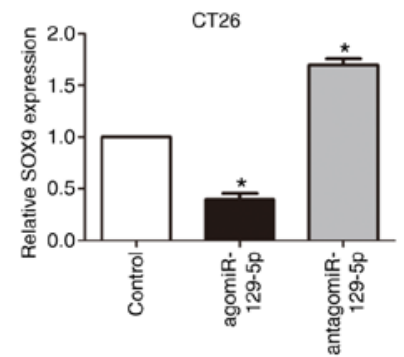

CT26

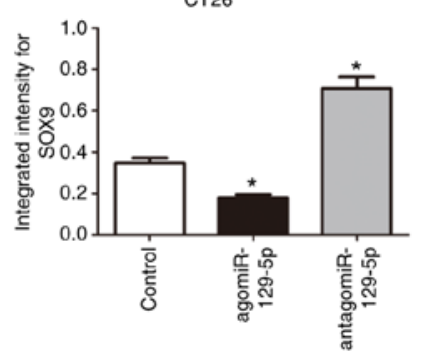

$\mathrm{G}$
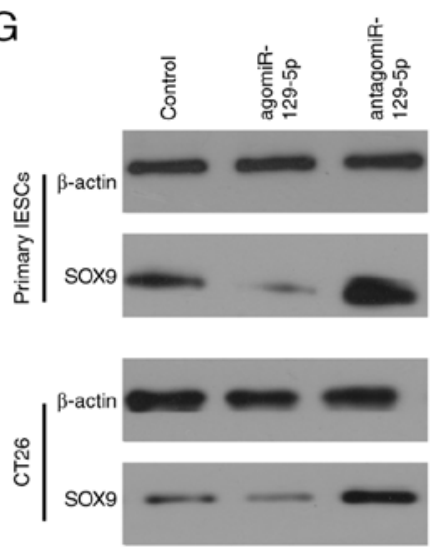

Figure 5. miR-129-5p regulates $\beta$-catenin expression by targeting SOX9. (A) mRNA levels of $\beta$-catenin expression in primary IECs and CT26 cells after transfection of antagomiR-129-5p or agomiR-129-5p. (B) Representative image and (C) quantification of $\beta$-catenin protein expression in primary IECs and CT26 cells after transfection of antagomiR-129-5p or agomiR-129-5p. These bar charts demonstrate that miR-129-5p regulates $\beta$-catenin expression. (D) The miR-129-5p binding site in the SOX9 sequence in mice. (E) Luciferase activity analysis in primary IESCs and CT26 cells. (F) mRNA expression of SOX9 in primary IECs and CT26 cells after transfection of antagomiR-129-5p or agomiR-129-5p. (G) Representative image and (H) quantification of western blots of SOX9 in primary IESCs and IEC-6 cells after transfection of miRNA mimic or inhibitor. $\mathrm{n}=6$; ${ }^{*} \mathrm{P}<0.05$ vs. control group; ${ }^{\sharp} \mathrm{P}<0.05$ vs. mutant group). IESCs, intestinal epithelial stem cells; miRNA/miR, microRNA; WT, wild type; MUT, mutant; agomiR, agonist miR; antagomiR, antagonist miR; SOX9, SRY-box 9; UTR, untranslated region.

to reduce or eliminate the effects of ceRNAs on their native mRNA targets. With the help of bioinformatics analysis,
MALAT1 was confirmed to harbor miR-129-5p binding sites. To further clarify this, the association between MALAT1 and 

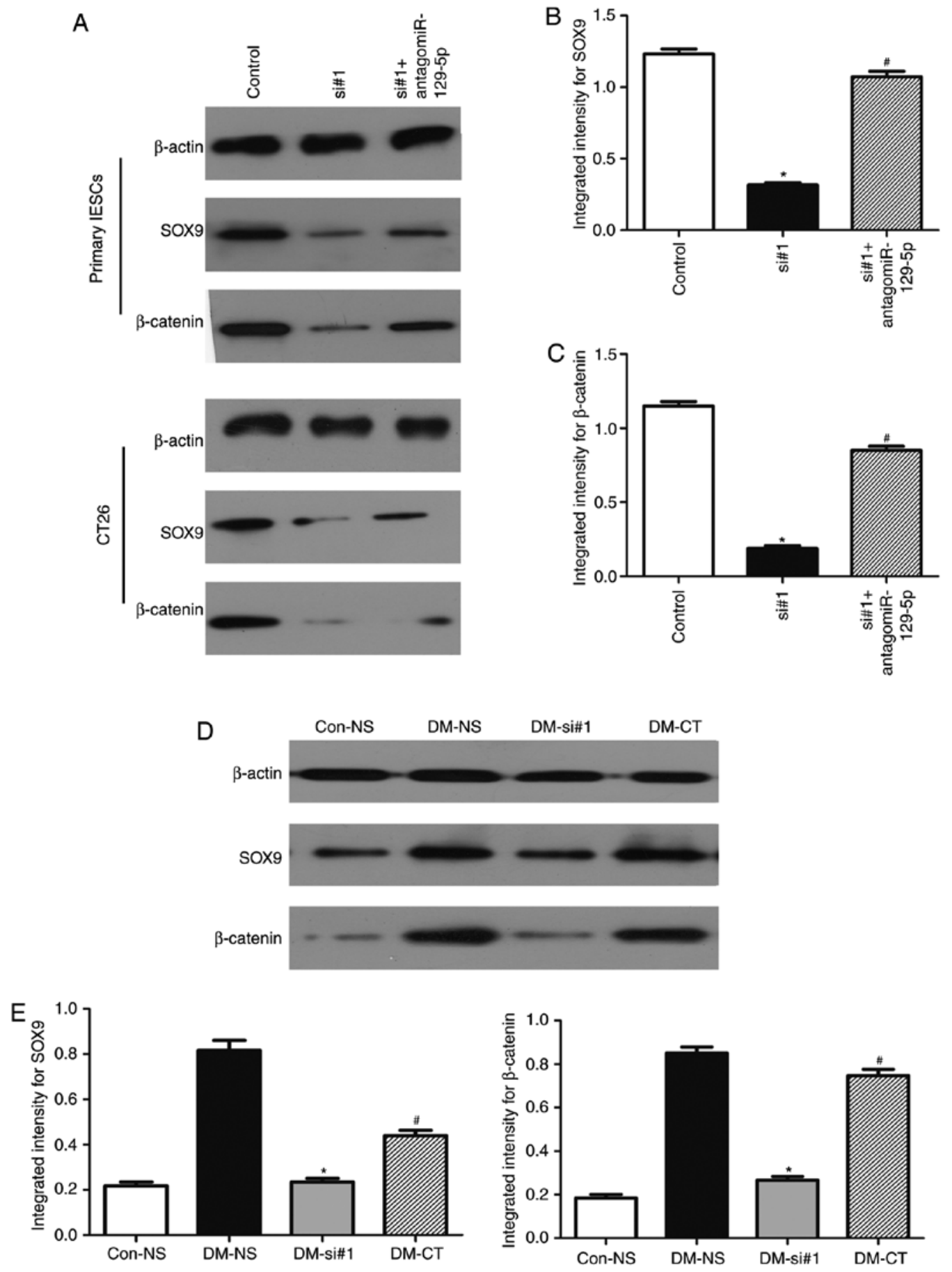

Figure 6. MALAT1 knockdown induces the downregulation of $\beta$-catenin levels. (A) The levels of SOX9 and $\beta$-catenin in primary IECs and CT26 after transfection with siRNAs or co-transfection with antagomiR-129-5p and siRNAs were determined by western blotting analysis. Quantification of (B) SOX9 and $(\mathrm{C}) \beta$-catenin protein levels. $\mathrm{n}=6$; ${ }^{*} \mathrm{P}<0.05$ vs. $\mathrm{NC}$; ${ }^{"} \mathrm{P}<0.05$ vs. siRNA groups. (D) Representative image and (E) quantification of the protein levels of miR-129-5p targets in DM mice after tail vein injections of siRNAs or cotransfection with antagomiR-129-5p or siRNAs. $n=6$; "P<0.05 vs. DM-NS group; ${ }^{\#} \mathrm{P}<0.05$ vs. DM-siRNAs group). IESCs, intestinal epithelial stem cells; miRNA/miR, microRNA; siRNA/si, small interfering RNA; antagomiR, antagonist miR; SOX9, SRY-box 9; MALAT1, metastasis associated lung adenocarcinoma transcript 1; Con-NS, control mice receiving saline; DM-NS, DM mice receiving saline; DM-si, DM mice receiving siRNA; DM-CT, DM mice receiving antagomiR-129-5p and MALAT1 siRNAs.

miR-129-5p was analyzed by performing luciferase assays. Restoration of miR-129-5p levels reduced MALAT1 levels, whereas antagonism of miR-129-5p increased MALAT1 expression. These studies indicate that miR-129-5p directly inhibits MALAT1 expression by directly targeting MALAT1.

As a class of nucleic acid-based molecules, miRNAs have therapeutic potential, depending on their characteristics, to modulate one or more gene targets within a particular signal transduction pathway, or even one or more targets across multiple independent pathways (38). Study has also confirmed the important role of miRNAs in the abnormal proliferation of cancer stem cells (39). Studies have shown that miR-129-5p plays important roles in regulating the proliferation of various human cancer types (40) and in 
diabetes (41). However, in the diabetic context, the mechanism of miR-129-5p actions in the proliferation of IESCs remains unclear. In the present study, bioinformatics analysis suggested that SOX9 was a target of miR-129-5p. To further confirm that SOX9 was a target of miR-129-5p, the effect of cotransfection of the miR-129-5p and SOX9-WNT plasmids was investigated by evaluating luciferase activity. The analysis showed that luciferase expression in cells cotransfected with miR-129-5p and the SOX9-WT plasmid was significantly decreased compared with that in cells cotransfected with miR-129-5p and the SOX9-MUT plasmid or transfected with the SOX9-WT plasmid alone. Thus, the luciferase reporter analysis confirmed that SOX9 is a target gene of miR-129-5p. To further confirm the association between miR-129-5p and SOX9, SOX9 expression was evaluated in primary IESCs and CT26 cells after transfection of miR-129-5p mimic or inhibitor. It was found that SOX9 expression was decreased at the mRNA and protein levels after upregulation of miR-129-5p expression. In contrast, downregulation of miR-129-5p expression increased SOX9 expression at the mRNA and protein levels. These results confirm that miR-129-5p could directly target SOX9 and suggest a potential mechanism for regulating SOX9 expression. Our previous study showed that SOX9 regulates $\mathrm{WNT} / \beta$-catenin signaling in IESCs in the diabetic context (30).

In mammals, the $\mathrm{WNT} / \beta$-catenin signaling pathway is essential for maintaining IESC proliferation and IEC homeostasis (42-44). The effect of MALAT1 on the Wnt/ $\beta$-catenin pathway has not been fully investigated under diabetic conditions. To further elucidate the underlying molecular mechanism of abnormal IESC proliferation in DM, the expression of MALAT1 in DM was examined by transfecting siRNAs in vitro and in vivo. After transfection of siRNA in primary IECs and DM mice, the downregulation of MALAT1 inhibited the expression of SOX9 and $\beta$-catenin, in a similar manner to that of the miR-129-5p mimic. Furthermore, lowering the expression of miR-129-5p partially offset the silencing effect of MALAT1 on these genes. Therefore, the effect of MALAT1 on IESC proliferation in DM could be explained in part by its function as a molecular sponge of miR-129-5p, thereby confirming the role of MALAT1 in the regulatory mechanism of IESC proliferation. A study has demonstrated that the upregulation of MALAT1 is induced by activation of the $\mathrm{Wnt} / \beta$-catenin pathway (45). However, there are numerous reports on MALAT1-mediated regulation of $\beta$-catenin expression $(26,46)$. In this study, in the context of diabetes, the downregulation of MALAT1 was demonstrated to inhibit the expression of SOX9 and $\beta$-catenin. We hypothesize that in the complex signaling networks of cells, adjustments between MALAT1 and $\beta$-catenin may occur through direct or indirect means, which may depend on different conditions. Thus, there is a need for more research in the diabetic context.

The results of the present study showed that IESC proliferation depended partly on MALAT1 expression. The potential mechanisms underlying these effects involve the regulation of the WNT/ $\beta$-catenin signaling pathways, MALAT1 actions as a molecular sponge for miR-129-5p and MALAT1-mediated regulation of its target gene SOX9. Furthermore, evidence for an apoptotic mechanism that serves to govern the proliferation of IESCs in DM was provided, offering a platform for the development of targeted therapeutics.

\section{Acknowledgements}

This study was supported by the National Natural Science Foundation of China (grant no. 81800461).

\section{Funding}

No funding was received.

\section{Availability of data and materials}

All data generated or analyzed during this study are included in this published article.

\section{Authors' contributions}

TDS conceived the study, wrote the original draft, collected the data for the proliferation of IESCs and investigated the SOX9-mediated WNT/ $\beta$-catenin signaling pathway in mice. ZBT collected the expression data of MALAT1 in mice. YPJ collected the data for the number of SOX9-positive cells. TDS and ZBT provided the resources and supervised the study. TDS and YPJ reviewed and edited the manuscript. All authors read and approved the final manuscript.

\section{Ethics approval and consent to participate}

The study was approved by the Ethics Committee of the Affiliated Hospital of Qingdao University (Qingdao, China).

\section{Patient consent for publication}

Not applicable.

\section{Competing interests}

The authors declare that they have no competing interests.

\section{References}

1. Davies MJ, D'Alessio DA, Fradkin J, Kernan WN, Mathieu C, Mingrone G, Rossing P, Tsapas A, Wexler DJ and Buse JB: Management of hyperglycemia in type 2 diabetes, 2018. A consensus report by the american diabetes association (ADA) and the European association for the study of diabetes (EASD). Diabetes Care 41: 2669-2701, 2018.

2. Nickerson HD and Dutta S: Diabetic complications: Current challenges and opportunities. J Cardiovasc Transl Res 5: 375-379, 2012.

3. Meldgaard T, Olesen SS, Farmer AD, Krogh K, Wendel AA, Brock B, Drewes AM and Brock C: Diabetic enteropathy: From molecule to mechanism-based treatment. J Diabetes Res 2018: $3827301,2018$.

4. de Kort S, Simons C, van den Brandt PA, Janssen-Heijnen MLG, Sanduleanu S, Masclee AAM and Weijenberg MP: Diabetes mellitus, genetic variants in the insulin-like growth factor pathway and colorectal cancer risk. Int J Cancer 145: 1774-1781, 2019.

5. Wang X, Häring MF, Rathjen T, Lockhart SM, Sørensen D, Ussar S, Rasmussen LM, Bertagnolli MM, Kahn CR and Rask-Madsen C: Insulin resistance in vascular endothelial cells promotes intestinal tumour formation. Oncogene 36: 4987-4996, 2017. 
6. Pirogov SA, Gvozdev VA and Klenov MS: Long noncoding RNAs and stress response in the nucleolus. Cells 8: E668, 2019.

7. Rafiee A, Riazi-Rad F, Havaskary M and Nuri F: Long noncoding RNAs: Regulation, function and cancer. Biotechnol Genet Eng Rev 34: 153-180, 2018.

8. Klingenberg M, Matsuda A,Diederichs S and Patel T: Non-coding RNA in hepatocellular carcinoma: Mechanisms, biomarkers and therapeutic targets. J Hepatol 67: 603-618, 2017.

9. Phelps M, Coss C, Wang H and Cook M: Registered report: Coding-independent regulation of the tumor suppressor PTEN by competing endogenous mRNAs. Elife 5: e12470, 2016.

10. Shan TD, Lv SY, Tian ZB, Liu XS, Liu FG and Sun XG: Knockdown of lncRNA H19 inhibits abnormal differentiation of small intestinal epithelial cells in diabetic mice. J Cell Physiol 234: 837-848, 2018.

11. Krishnan P and Damaraju S: The challenges and opportunities in the clinical application of noncoding RNAs: The road map for miRNAs and piRNAs in cancer diagnostics and prognostics. Int J Genomics 2018: 5848046, 2018.

12. Wu S, Sun H, Wang Y, Yang X, Meng Q, Yang H, Zhu H, Tang W, Li X, Aschner M and Chen R: MALAT1 rs664589 polymorphism inhibits binding to miR-194-5p, contributing to colorectal cancer risk, growth, and metastasis. Cancer Res 79: 5432-5441, 2019.

13. Wang $\mathrm{D}, \mathrm{Xu} \mathrm{H}, \mathrm{Wu} \mathrm{B}$, Jiang $\mathrm{S}$, Pan $\mathrm{H}$, Wang $\mathrm{R}$ and Chen $\mathrm{J}$ : Long noncoding RNA MALAT1 sponges miR1243p.1/KLF5 to promote pulmonary vascular remodeling and cell cycle progression of pulmonary artery hypertension. Int J Mol Med 44: 871-884, 2019.

14. Tay Y, Kats L, Salmena L, Weiss D, Tan SM, Ala U, Karreth F, Poliseno L, Provero P, Di Cunto F, et al: Coding-independent regulation of the tumor suppressor PTEN by competing endogenous mRNAs. Cell 147: 344-357, 2011.

15. Cesana M, Cacchiarelli D, Legnini I, Santini T, Sthandier O, Chinappi M, Tramontano A and Bozzoni I: A long noncoding RNA controls muscle differentiation by functioning as a competing endogenous RNA. Cell 147: 358-369, 2011.

16. Thyagarajan A, Shaban A and Sahu RP: MicroRNA-directed cancer therapies: Implications in melanoma intervention. J Pharmacol Exp Ther 364: 1-12, 2018.

17. Shan TD, Ouyang H, Yu T, Li JY, Huang CZ, Yang HS, Zhong W, Xia ZS and Chen QK: miRNA-30e regulates abnormal differentiation of small intestinal epithelial cells in diabetic mice by downregulating Dll4 expression. Cell Prolif 49: 102-114, 2016.

18. Hou S, Lin Q, Guan F and Lin C: IncRNA TNRC6C-AS1 regulates UNC5B in thyroid cancer to influence cell proliferation, migration, and invasion as a competing endogenous RNA of miR-129-5p. J Cell Biochem 119: 8304-8316, 2018.

19. Wu C, Zhang X, Chen P, Ruan X, Liu W, Li Y, Sun C, Hou L, Yin B, Qiang B, et al: MicroRNA-129 modulates neuronal migration by targeting Fmrl in the developing mouse cortex. Cell Death Dis 10: 287, 2019.

20. Li Z, Lu J, Zeng G, Pang J, Zheng X, Feng J and Zhang J: MiR-129-5p inhibits liver cancer growth by targeting calcium calmodulin-dependent protein kinase IV (CAMK4). Cell Death Dis 10: 789, 2019.

21. Clevers H, Loh KM and Nusse R: Stem cell signaling. An integra program for tissue renewal and regeneration: Wnt signaling and stem cell control. Science 346: 1248012, 2014.

22. Perochon J, Carroll LR and Cordero JB: Wnt signalling in intestinal stem cells: Lessons from mice and flies. Genes (Basel) 9: E138, 2018.

23. Dorfman T, Pollak Y, Sohotnik R, Coran AG, Bejar J and Sukhotnik I: Enhanced intestinal epithelial cell proliferation in diabetic rats correlates with beta-catenin accumulation. J Endocrinol 226: 135-143, 2015.

24. Ouyang H, Yang HS, Yu T, Shan TD, Li JY, Huang CZ, Zhong W, Xia ZS and Chen QK: MEK/ERK pathway activation by insulin receptor isoform alteration is associated with the abnormal proliferation and differentiation of intestinal epithelial cells in diabetic mice. Mol Cell Biochem 413: 165-178, 2016.

25. Liu S, Qiu J, He G, Liang Y, Wang L, Liu C and Pan H: lncRNA MALAT1 acts as a miR-125a-3p sponge to regulate FOXM1 expression and promote hepatocellular carcinoma progression. J Cancer 10: 6649-6659, 2019.

26. Zhang J, Li Q, Xue B and He R: MALAT1 inhibits the Wnt//-catenin signaling pathway in colon cancer cells and affects cell proliferation and apoptosis. Bosn J Basic Med Sci: Nov 15 2019 (Epub ahead of print). doi: 10.17305/bjbms.2019.4408.
27. Wu X,Li R, Song Q, Zhang C, Jia R, Han Z, Zhou L, Sui H, Liu X, $\mathrm{Zhu} \mathrm{H}$, et al: JMJD2C promotes colorectal cancer metastasis via regulating histone methylation of MALAT1promoter and enhancing $\beta$-catenin signaling pathway. J Exp Clin Cancer Res 38: 435, 2019.

28. Brito-Casillas Y, Melian C and Wagner AM: Study of the pathogenesis and treatment of diabetes mellitus through animal models. Endocrinol Nutr 63: 345-353, 2016.

29. Livak KJ and Schmittgen TD: Analysis of relative gene expression data using real-time quantitative PCR and the 2(-Delta Delta $\mathrm{C}(\mathrm{T})$ ) method. Methods 25: 402-408, 2001.

30. Huang CZ, Xu JH, Zhong W, Xia ZS, Wang SY, Cheng D, Li JY, Wu TF, Chen QK and Yu T: Sox9 transcriptionally regulates Wnt signaling in intestinal epithelial stem cells in hypomethylated crypts in the diabetic state. Stem Cell Res Ther 8: 60, 2017.

31. Gracz AD, Ramalingam S and Magness ST: Sox9 expression marks a subset of CD24-expressing small intestine epithelial stem cells that form organoids in vitro. Am J Physiol Gastrointest Liver Physiol 298: G590-G600, 2010.

32. Dhamija S and Diederichs S: From junk to master regulators of invasion: lncRNA functions in migration, EMT and metastasis. Int J Cancer 139: 269-280, 2016.

33. Lv SY, Shan TD, Pan XT, Tian ZB, Liu XS, Liu FG, Sun XG, Xue HG, Li XH, Han Y, et al: The lncRNA ZEB1-AS1 sponges miR-181a-5p to promote colorectal cancer cell proliferation by regulating Wnt/beta-catenin signaling. Cell Cycle 17: 1245-1254, 2018.

34. Yu T, Shan TD, Li JY, Huang CZ, Wang SY, Ouyang H, Lu XJ, $\mathrm{Xu} \mathrm{JH}$, Zhong $\mathrm{W}$ and Chen QK: Knockdown of linc-UFC1 suppresses proliferation and induces apoptosis of colorectal cancer. Cell Death Dis 7: e2228,2016.

35. Koren E, Yosefzon Y, Ankawa R, Soteriou D, Jacob A, Nevelsky A, Ben-Yosef R, Bar-Sela G and Fuchs Y: ARTS mediates apoptosis and regeneration of the intestinal stem cell niche. Nat Commun 9: 4582, 2018.

36. Ballantyne MD, McDonald RA and Baker AH: lncRNA MicroRNA interactions in the vasculature. Clin Pharmacol Ther 99: 494-501, 2016.

37. Adams BD, Parsons C, Walker L, Zhang WC and Slack FJ: Targeting noncoding RNAs in disease. J Clin Invest 127: 761-771, 2017.

38. Khawar MB, Mehmood R and Roohi N: MicroRNAs: Recent insights towards their role in male infertility and reproductive cancers. Bosn J Basic Med Sci 19: 31-42, 2019.

39. Tian Y, Ma X, Lv C, Sheng X, Li X, Zhao R, Song Y, Andl T, Plikus MV, Sun J, et al: Stress responsive miR-31 is a major modulator of mouse intestinal stem cells during regeneration and tumorigenesis. Elife 6: e29538, 2017.

40. Shaker OG, Abdelwahed MY, Ahmed NA, Hassan EA, Ahmed TI, Abousarie MA and Ayoub SE: Evaluation of serum long noncoding RNA NEAT and MiR-129-5p in hepatocellular carcinoma. IUBMB Life 71: 1571-1578, 2019.

41. Demirsoy İH, Ertural DY, Balci S, Cınkır Ü, Sezer K, Tamer L and Aras N: Profiles of circulating MiRNAs following metformin treatment in patients with type 2 diabetes. J Med Biochem 37: 499-506, 2018

42. Mao J, Hu X, Xiao Y, Yang C, Ding Y, Hou N, Wang J, Cheng H and Zhang X: Overnutrition stimulates intestinal epithelium proliferation through beta-catenin signaling in obese mice. Diabetes 62: 3736-3746, 2013.

43. Bello SA, Torres-Gutiérrez V, Rodríguez-Flores EJ, Toledo-Román EJ, Rodríguez N, Díaz-Díaz LM, VázquezFigueroa LD, Cuesta JM, Grillo-Alvarado V, Amador A, et al: Insights into intestinal regeneration signaling mechanisms. Dev Biol: Feb 1, 2020 (Epub ahead of print). doi: 10.1016/j. ydbio.2019.10.005

44. Merenda A, Fenderico N and Maurice MM: Wnt signaling in 3D: Recent advances in the applications of intestinal organoids. Trends Cell Biol 30: 60-73, 2020

45. Li H, Zhao Q, Chang L, Wei C, Bei H, Yin Y, Chen M, Wang H, Liang $J$ and $\mathrm{Wu}$ Y: IncRNA MALAT1 modulates ox-LDL induced EndMT through the Wnt/ $\beta$-catenin signaling pathway. Lipids Health Dis 18: 62, 2019.

46. Guo C, Wang X, Chen LP, Li M, Li M, Hu YH, Ding WH and Wang X: Long non-coding RNA MALAT1 regulates ovarian cancer cell proliferation, migration and apoptosis through Wnt $/ \beta$-catenin signaling pathway. Eur Rev Med Pharmacol Sci 22: 3703-3712, 2018. 